\title{
Effectiveness and acceptability of lidocaine spray in reducing perineal pain during spontaneous vaginal delivery: randomised controlled trial
}

\author{
Julia Sanders, Tim J Peters, Rona Campbell
}

\begin{abstract}
Objectives To evaluate the effectiveness and acceptability of a lidocaine spray in reducing perineal pain during spontaneous vaginal delivery.

Design Randomised controlled trial.

Setting Consultant led obstetric unit.

Participants 185 women who had a spontaneous vaginal delivery without epidural analgesia.

Interventions Topically applied local anaesthetic spray (93 women) and placebo spray (92 women).

Main outcome measure Primary outcome measure was pain during delivery (0-100 scale). The 16 secondary outcome measures included second degree perineal trauma during delivery, trauma of the genital tract, and dyspareunia by two months.

Results Lidocaine spray did not reduce pain during spontaneous vaginal delivery: mean 77 and 72 on a scale of $0-100$ in the lidocaine and placebo groups, respectively (difference between means 4.8, 95\% confidence interval -1.7 to 11.2). Lidocaine spray may reduce genital tract trauma during delivery, in particular second degree perineal trauma. The intervention was highly acceptable to the women and midwives. Conclusions Although lidocaine spray applied to the perineum during spontaneous vaginal delivery did not reduce perineal pain, it was acceptable to both the women and the midwives. Trial registration Current controlled trials ISRCTN99732966.
\end{abstract}

\section{Introduction}

Numerous studies have been published on analgesia during labour. ${ }^{1}$ Yet it is common for women having spontaneous vaginal delivery not to be offered analgesia for perineal pain during second stage labour. A national survey of UK midwifery practice found that midwives applied a variety of substances to the perineum to reduce pain, including lidocaine in a few cases. ${ }^{2}$ Although midwives considered these techniques to be effective, none has been rigorously evaluated. Moreover, many randomised trials of management of second stage labour, including analgesics, have not measured pain experienced by the mother. ${ }^{3}$

Although care of the perineum has been extensively researched, studies have focused on preventing trauma, including episiotomy, rather than on reducing pain explicitly. ${ }^{5-8}$ We compared the effectiveness of a local anaesthetic spray with a placebo spray in reducing perineal pain in women having a spontaneous vaginal delivery. We also ascertained the views of the women and midwives on acceptability of the sprays.

\section{Participants and methods}

Between February 2003 and May 2004 midwives provided written and verbal information about the trial to potentially eligible women more than 30 weeks' pregnant who attended antenatal clinics in the area served by the participating hospital. The midwife placed a sticker on the maternity notes indicating whether the woman was ineligible, had declined participation in the trial, or had expressed an interest. Exclusion criteria during the antenatal period were multiple pregnancy; booked in for a caesarean section, instrumental delivery, or episiotomy; previous adverse reaction to a local anaesthetic; and insufficient English to provide consent or complete the study questionnaires. Exclusion criteria during the intrapartum period were pregnancy less than 37 weeks' gestation, epidural analgesia, non-cephalic presentation, and baby expected to require intensive neonatal care after delivery.

Women who had expressed an interest in the trial were identified by hospital based midwives when they were admitted to hospital in labour or for induction of labour. After checking eligibility and obtaining written consent, the midwife asked a member of the medical staff to prescribe the trial solution. Before randomisation the attending midwife reconfirmed the woman's consent to participate.

\section{Trial interventions}

The active trial solution was formulated to equate to Xylocaine spray (AstraZeneca, Bedfordshire), omitting cosmetic ingredients. The active and placebo trial solutions were of similar appearance, consistency, and odour. Attending midwives were instructed to apply five sprays of the solution, each of $0.1 \mathrm{ml}$, to the woman's perineum and inside aspect of the labia once spontaneous birth was imminent. Spraying was to be suspended if the fetal head had advanced such that the dosage could not be completed before the midwife needed to prepare for delivery. The number of sprays administered was recorded, and the time between application and delivery was calculated. The five sprays were to be administered at least three minutes before delivery to have time to take effect.

\section{Assignment}

Randomisation was undertaken by an independent agency, which produced and packaged the trial solutions. Allocation was on a 1:1 basis using computer generated random permuted blocks of $10 .{ }^{9}$ The placebo and active trial solutions $(5 \mathrm{ml}$ each) 
were packaged in identical bottles. Each was labelled with a unique trial number and placed in a sealed trial box. Women were randomised when the attending midwife judged spontaneous vaginal delivery imminent, and the next consecutive trial box was opened.

\section{Outcome measures}

The primary outcome was pain during delivery, self reported before leaving the delivery suite and assessed on a 0-100 scale from 0 (no pain) to 100 (worst possible pain). The 16 secondary outcomes were: delivery pain by a four level ordered categorical assessment of severity and the adapted McGill pain questionnaire (short form) total score ${ }^{10}$; satisfaction with analgesia; second degree perineal trauma (including women who had an episiotomy); genital tract trauma and its management; feelings during delivery ${ }^{11}$; overall rating of birth experience ${ }^{12}$; perineal pain one week after delivery; resumption of intercourse by two months; dyspareunia by two months; maternal adjustment to motherhood $^{13}$; and condition of the baby at birth. Nonresponders to questionnaires were sent a reminder letter after two weeks and a letter and additional questionnaire after four weeks. Midwives collected a sample of cord blood for ascertainment of lidocaine levels. They also completed a questionnaire on deliveries. We obtained data on sociodemographic characteristics and the acceptability of the intervention to women through a questionnaire given $6-8$ days after delivery. Acceptability to 14 midwives was ascertained through semistructured interviews, the transcripts of which were subjected to a thematic analysis.

\section{Sample size}

In a pilot study carried out at the trial site, the levels of pain experienced by 67 women without epidural analgesia during spontaneous vaginal delivery were ascertained on the primary pain outcome, yielding a mean 65.3 (SD 25.7). We considered as clinically significant a reduction in pain during delivery of 0.5 standard deviations (13 scale points); 180-212 women were required to detect such a difference with $85 \%-90 \%$ power and a two sided $5 \%$ significance level, allowing conservatively for $20 \%$ attrition.

\section{Analysis}

We analysed the data using SPSS. The primary comparative analyses were carried out on an intention to treat basis, with data analysts blind to treatment group. We used regression analysis to compare the outcomes between groups. Secondary analyses also involved regression models: firstly, adjusting for variables that showed a potentially important imbalance at baseline; secondly, restricting analysis to those who received either spray fully in accordance with the protocol; and thirdly, including the relevant interaction to carry out a planned subgroup analysis according to whether or not it was the woman's first delivery. Perineal pain was the primary outcome. Before inspection of the data, we considered possible mechanisms by which the intervention might affect the primary outcome. As a consequence we identified perineal trauma as a secondary outcome of particular interest. The reason for this was that perineal pain could be closely related to perineal integrity. For example, reduced pain might be associated with increased perineal trauma if the birth was accelerated by the intervention. We therefore calculated the number needed to treat for perineal trauma, along with a $95 \%$ confidence interval. ${ }^{14}$

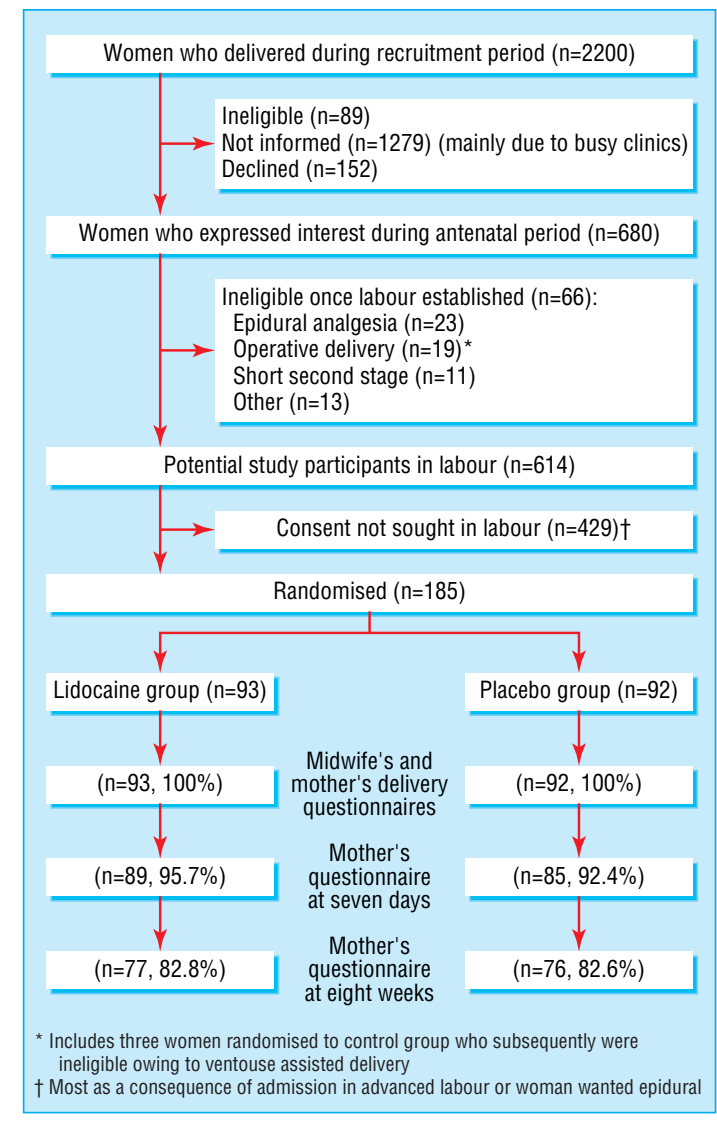

Fig 1 Flow of participants through trial and response rates

\section{Results}

Of the 2200 women delivering at the participating unit during the recruitment period, 680 were interested during their antenatal period in participating (fig 1). Of these, 66 became ineligible once in labour and three had been randomised but had ventouse assisted delivery, precluding use of the spray. These women were excluded from analyses because their primary outcomes could not have been influenced by the intervention and the decision on delivery method was independent of trial allocation. Consent was not sought in labour from a further 429 women, due primarily to admission in advanced labour or request for an epidural. All 185 women approached in labour provided consent and were randomised: 93 to lidocaine spray and 92 to placebo spray.

Characteristics at baseline and delivery of the interventions

The women in the trial groups were similar for several baseline obstetric and sociodemographic characteristics, apart from smoking, parity, augmentation, induction, use of pethidine before randomisation, and birth weight (table 1). Since these variables could be associated with the outcomes they were adjusted for in secondary analyses.

The mean (SD) number of sprays administered in both groups was $4.8(0.9)$. Almost two thirds of women received the intervention as intended. The mean difference in time between intervention and delivery was also similar between the groups: lidocaine group 11.0 minutes and placebo group 12.5 minutes. Although these times varied between individual women (standard deviations of about 10 minutes), about $80 \%$ of women delivered within 15 minutes of receiving the spray in both groups. 
Table 1 Baseline characteristics of women assigned to lidocaine spray topically applied to the perineum or to placebo spray. Values are numbers (percentages) unless stated otherwise

\begin{tabular}{|c|c|c|}
\hline Characteristic & $\begin{array}{l}\text { Lidocaine group } \\
\qquad(\mathrm{n}=93)\end{array}$ & Placebo group ( $n=92)$ \\
\hline Mean (SD) age (years) & $29.7(6.6)$ & $28.4(5.5)$ \\
\hline \multicolumn{3}{|l|}{ Partner status: } \\
\hline Live with partner & $76(87)$ & $74(87)$ \\
\hline Live apart & $9(10)$ & $05(6)$ \\
\hline No partner & $2(2)$ & $6(7)$ \\
\hline \multicolumn{3}{|l|}{ Qualifications: } \\
\hline None & $9(10)$ & $13(15)$ \\
\hline GCSE or A levels & $30(35)$ & $19(22)$ \\
\hline $\begin{array}{l}\text { National vocational qualifications or } \\
\text { trade qualifications }\end{array}$ & $14(16)$ & $13(15)$ \\
\hline Degree or above & $20(23)$ & $20(24)$ \\
\hline Professional & $14(16)$ & $20(24)$ \\
\hline \multicolumn{3}{|l|}{ Current smoking: } \\
\hline Smoke every day & $8(9)$ & $16(19)$ \\
\hline Smoke occasionally & $4(5)$ & $8(9)$ \\
\hline Do not smoke & $76(86)$ & $61(72)$ \\
\hline \multicolumn{3}{|l|}{ Parity: } \\
\hline 0 & $39(42)$ & $42(46)$ \\
\hline 1 & $32(34)$ & $35(38)$ \\
\hline$\geq 2$ & $22(24)$ & $15(16)$ \\
\hline $\begin{array}{l}\text { Mean (SD) gestation (completed } \\
\text { weeks) }\end{array}$ & $39.8(1.2)$ & $39.8(1.2)$ \\
\hline Labour induced & $29(31)$ & $20(22)$ \\
\hline Labour augmented & $27(29)$ & $16(17)$ \\
\hline \multicolumn{3}{|l|}{ Pethidine used in labour: } \\
\hline Frequency & $58(62)$ & $50(54)$ \\
\hline Mean (SD) dose & $116(60.0)$ & $114(47.7)$ \\
\hline Mean (SD) birth weight $(\mathrm{g})$ & $3507(428)$ & $3626(507)$ \\
\hline Partner present & $83(94)$ & $78(91)$ \\
\hline
\end{tabular}

Numbers vary slightly owing to missing data

Blinding was successfully maintained in the women and midwives, with neither group able to identify the trial solution with any accuracy beyond chance. Of the 88 cord blood samples collected from women who had received lidocaine, 86 contained low or very low levels of lidocaine and two contained levels at the upper limit of the therapeutic range ( 5.60 and $5.70 \mu \mathrm{g} / \mathrm{ml}$; fig 2).

Ten women in the lidocaine group and six in the placebo group reported an unpleasant experience with the spray. In contrast, 32 women in the lidocaine group compared with 22 in the placebo group reported either a cooling or analgesic effect. The midwives unanimously considered perineal analgesia during second stage labour to be an acceptable addition to current practice.

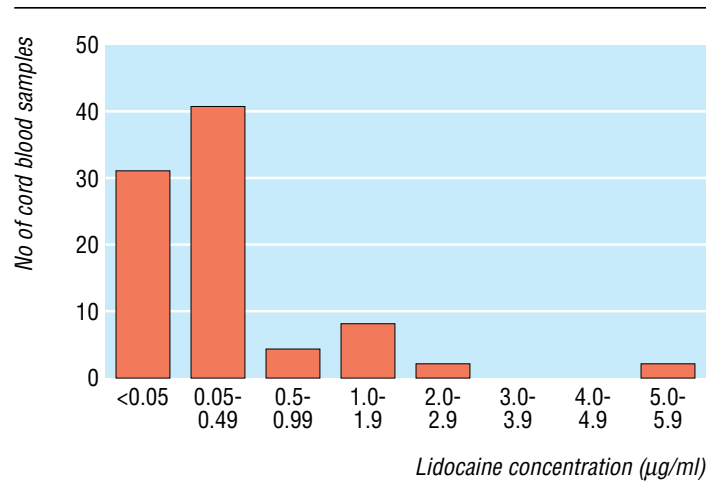

Fig 2 Lidocaine levels $(\mu \mathrm{g} / \mathrm{ml})$ in cord blood
Table 2 Comparison of perineal pain between women assigned to lidocaine spray topically applied to the perineum or to placebo spray. Values are means (SDs) unless stated otherwise

\begin{tabular}{lcccc} 
& $\begin{array}{c}\text { Lidocaine } \\
\text { group }(\mathrm{n}=91)\end{array}$ & $\begin{array}{c}\text { Placebo } \\
\text { group }(\mathrm{n}=90)\end{array}$ & $\begin{array}{c}\text { Difference between } \\
\text { means }(95 \% \mathrm{Cl})\end{array}$ & P value \\
\hline Perineal pain $^{*}$ & $76.9(21.6)$ & $72.1(22.2)$ & $4.8(-1.7$ to 11.2$)$ & 0.14
\end{tabular}

Positive difference between means indicates increase in pain for lidocaine spray compared with placebo spray.

${ }^{*}$ Scale from 0 (no pain) to 100 (worst possible pain).

\section{Primary outcome}

Mean pain scores were high and similar for both groups. No evidence was found of a sizeable reduction in pain using lidocaine spray compared with placebo spray (table 2); the suggestion was that pain may have been slightly increased.

Adjusting for imbalances at baseline had little effect on the results, as did restricting the analysis to the 124 women who received five doses of the lidocaine spray as intended at least three minutes before delivery (table 3). Although power is limited for subgroup analysis, no evidence was found that the effect of the intervention differed by parity.

\section{Secondary outcomes}

Most secondary outcomes were similar between the groups (table 4). However, a smaller proportion of women who received the lidocaine spray compared with the placebo spray sustained second degree perineal trauma. Of the 59 women in the lidocaine group and 67 in the placebo group who sustained any genital tract trauma, 17 and 14, respectively, experienced first degree perineal trauma, and 26 and 41 experienced second degree perineal trauma, including two and eight women who had an episiotomy. No woman in either group sustained third degree or fourth degree perineal trauma. Women in the lidocaine group were also less likely to experience dyspareunia when resuming sexual intercourse.

\section{Discussion}

Although a local anaesthetic (lidocaine) spray applied to the perineum of women during spontaneous vaginal delivery was acceptable to the women and midwives, it was not associated with any reduction in perineal pain; if anything the trend was to worse pain. The intervention may reduce the occurrence of second degree perineal trauma and have longer term benefits-namely, a reduction in the proportion of women reporting dyspareunia two months after delivery. These findings seem to be contradictory. This may be because the findings are due to chance or because the spray enables a more controlled delivery of the fetal head and therefore prolongs this process. If so, the intervention could prevent trauma while not reducing pain. Further studies, including randomised trials, are needed to confirm or refute the findings of perineal trauma.

Table 3 Secondary analyses of pain during delivery adjusting for six baseline factors and restricting analyses to women who, as intended, received five doses of lidocaine spray at least three minutes before delivery

\begin{tabular}{lcc} 
& Difference between means $(95 \%$ Cl $)$ & P value \\
\hline Perineal pain score ${ }^{\star}(n=169)$ & $6.3(-0.8$ to 13.3$)$ & 0.081 \\
\hline Perineal pain score $+(n=124)$ & $6.8(-0.4$ to 14.0$)$ & 0.065 \\
\hline
\end{tabular}

Positive difference in means indicates increase in delivery pain for lidocaine spray compared with placebo spray.

${ }^{*}$ Adjusted for imbalance at baseline in smoking, parity, augmentation, induction, use of pethidine before randomisation, and birth weight.

†Among women who received intervention as intended. 
Table 4 Comparison of secondary outcomes between women assigned to lidocaine spray topically applied to the perineum or to placebo spray. Values are percentages (denominators) unless stated otherwise

\begin{tabular}{|c|c|c|c|c|}
\hline Secondary outcomes & $\begin{array}{l}\text { Lidocaine } \\
\text { group }\end{array}$ & $\begin{array}{l}\text { Placebo } \\
\text { group }\end{array}$ & $\begin{array}{l}\text { Difference between } \\
\text { means or risk ratio } \\
(95 \% \mathrm{Cl})\end{array}$ & $P$ value \\
\hline $\begin{array}{l}\text { Mean (SD) pain } \\
\text { severity }\end{array}$ & 3.5 (92) & $3.6(92)$ & $-0.1 \quad(-0.3$ to 0.1$)$ & 0.33 \\
\hline $\begin{array}{l}\text { Mean (SD) McGill } \\
\text { pain questionnaire } \\
\text { (short form) total } \\
\text { score }\end{array}$ & $33.9(91)$ & $34.9(91)$ & $-1.0(-3.5$ to 1.4$)$ & 0.41 \\
\hline $\begin{array}{l}\text { Considered analgesia } \\
\text { adequate }\end{array}$ & 78 (81) & 74 (72) & 1.06 (0.88 to 1.27$)$ & 0.55 \\
\hline $\begin{array}{l}\text { Experienced second } \\
\text { degree perineal } \\
\text { trauma }\end{array}$ & $28(93)$ & $45(92)$ & 0.63 (0.42 to 0.93$)$ & 0.019 \\
\hline Genital tract trauma & $63(93)$ & $73(92)$ & 0.87 (0.71 to 1.06$)$ & 0.17 \\
\hline Vaginal trauma & $20(93)$ & $12(92)$ & 1.71 (0.86 to 3.39$)$ & 0.12 \\
\hline Sutured after delivery & $38(93)$ & 49 (92) & 0.77 (0.55 to 1.08) & 0.12 \\
\hline $\begin{array}{l}\text { Mean (SD) feelings } \\
\text { during delivery }\end{array}$ & $31.0(77)$ & $32.1(80)$ & $-1.1 \quad(-3.3$ to 1.2$)$ & 0.37 \\
\hline $\begin{array}{l}\text { Mean (SD) overall } \\
\text { rating of birth } \\
\text { experience }\end{array}$ & $6.7(88)$ & $7.0(84)$ & $-0.3(-1.0$ to 0.4$)$ & 0.39 \\
\hline $\begin{array}{l}\text { Perineal pain one } \\
\text { week after delivery }\end{array}$ & $66(87)$ & $67(85)$ & 0.98 (0.79 to 1.21$)$ & 0.83 \\
\hline $\begin{array}{l}\text { Sexual intercourse } \\
\text { resumed eight } \\
\text { weeks after delivery }\end{array}$ & $65(77)$ & $74(74)$ & 0.87 (0.71 to 1.08 ) & 0.21 \\
\hline $\begin{array}{l}\text { Dyspareunia at eight } \\
\text { weeks after delivery }\end{array}$ & $27(92)$ & 53 (91) & 0.52 (0.35 to 0.76$)$ & 0.0004 \\
\hline $\begin{array}{l}\text { Mean (SD) maternal } \\
\text { adjustment and } \\
\text { maternal attitudes } \\
\text { score }\end{array}$ & $20.4(69)$ & $19.9(63)$ & $0.5(-1.0$ to 2.0$)$ & 0.49 \\
\hline $\begin{array}{l}\text { Mean (SD) Apgar } \\
\text { score at one } \\
\text { minute }\end{array}$ & $8.4(93)$ & $8.6(92)$ & $-0.2(-0.5$ to 0.2$)$ & 0.30 \\
\hline $\begin{array}{l}\text { Mean (SD) Apgar } \\
\text { score at five } \\
\text { minutes }\end{array}$ & 9.6 (93) & $9.6(92)$ & $-0.1(-0.2$ to 0.1$)$ & 0.59 \\
\hline $\begin{array}{l}\text { Baby received } \\
\text { resuscitation }\end{array}$ & $28(93)$ & $21(92)$ & 1.35 (0.81 to 2.27 ) & 0.25 \\
\hline
\end{tabular}

Negative difference in means indicates a reduction in mean outcome for lidocaine spray compared with placebo spray.

Risk ratio $<1$ indicates reduced risk of outcome for lidocaine spray compared with placebo spray.

The levels of lidocaine in the cord blood were almost always within acceptable limits except in two cases. These two exceptions may have occurred through contamination of the cord sample after delivery, placental transfer, or direct absorption through the fetal scalp during delivery. Placental transfer is unlikely at these levels. ${ }^{15-19}$ Contamination is also unlikely-the spray comprised free lidocaine in ethanol, which evaporates rapidly, and both lidocaine and ethanol were detected in the cord samples. Lidocaine hydrochloride does not readily permeate the skin of neonates, but free lidocaine as used here may do so. ${ }^{20}{ }^{21}$ If this hypothesis is confirmed by further research then there are implications for administration of the spray.

\section{Strengths and limitations of the trial}

This trial was powered to detect a difference in the primary outcome of perineal pain. In the event, the confidence interval for this outcome was moderately wide, including the null and extending close to the target difference in a direction not favouring lidocaine spray. The trial was not powered for binary outcomes, and the confidence intervals for secondary outcomes of this type, including second degree perineal trauma, were commensurately wide. The potential clinical implications of the finding for perineal trauma mean that it should be a primary outcome in future similar trials. Moreover, adequate sample size for perineal trauma would improve the precision of the estimate achieved here, as illustrated by the $95 \%$ confidence interval for the number needed to treat $(\mathrm{n}=6)$ for this outcome being from 4 to 25 .

In terms of generalisability, only one maternity unit was involved in the trial but a large number of midwives were involved in recruitment (34 in the community and 67 in the hospital), serving a wide geographical area encompassing a socioeconomically diverse population. In addition, recruitment took place over a considerable period (16 months). Although only a third of the 2200 women booked to deliver at the unit were approached antenatally about the trial, just $18 \%$ of invited women declined participation. All those who were eligible in labour were randomised.

Other strengths of the study include the successful blinding of the women, midwives, and data analysts; a high and similar level of adherence to the protocol for administration of the lidocaine and placebo sprays; and negligible attrition.

\section{Relation to the literature}

The pain scores recorded in this trial were similar to those obtained in previous studies of second stage labour, including high mean levels and considerable variability. ${ }^{22}{ }^{23}$ In keeping with the findings of previous randomised trials of second stage care, ${ }^{724}$ overall levels of genital trauma were higher than generally reported. This may result from trauma being recorded in more detail in the trial questionnaires than would normally be required in clinical notes or on a computer.

\section{Conclusions}

The use of a topically applied local anaesthetic during second stage labour was acceptable to women and midwives. The lidocaine spray during delivery did not, however, reduce perineal pain. The secondary findings relating to reductions in second degree perineal trauma and dyspareunia at two months after delivery need to be substantiated in further randomised trials. The potential clinical implications of these outcomes and the possible magnitudes of effect suggested in this trial mean that such research should be a priority.

We thank the women and midwives who participated in the study; Angela Ralli-Thomas and Mr Colin Ranshaw of St Mary's Pharmaceuticals, Cardiff; Mike Harmer for facilitating the study; and Jenny Donovan, Deirdre Murphy, and a reviewer for helpful comments.

Contributors: JS conceived the study. All authors obtained the funding, designed the study, and comprised the Trial Management Group. JS managed the trial on a day to day basis and carried out the analyses, supervised by RC and TJP. JS wrote the first draft of the paper. RC and TJP led the redrafting and attended to reviewer's comments. JS is guarantor.

\section{What is already known on this topic}

Spontaneous vaginal delivery is associated with severe pain and trauma to the genital tract, resulting in short and long term morbidity

Perineal analgesia is not normally offered to women having a spontaneous vaginal delivery

\section{What this study adds}

Perineal analgesia during second stage labour was acceptable to women and midwives

A lidocaine spray had no noticeable effect on perineal pain during spontaneous vaginal delivery 
Funding: This research was carried out while JS was in receipt of Medical Research Council/Wales Office of Research and Development special training fellowship in health services research, with additional funding for the trial provided by Wellbeing for Women and the Obstetric Anaesthetists Association.

Competing interests: None declared.

Ethical approval: This trial was approved by the Medicines Control Agency, the local research ethics committee and the participating NHS trust research and development directorate.

1 National Perinatal Epidemiology Unit. A classified bibliography of controlled trials in perinatal medicine 1940-1984. Oxford: Oxford University Press, 1986.

2 Sanders J, Peters TJ, Campbell R. Techniques to reduce perineal pain during spontaneous vaginal delivery and perineal suturing: a UK survey of midwifery practice Midwifery 2005;21:154-60

3 Gupta JK, Nikodem VC. Women's position during the second stage of labour. Cochrane Database Syst Rev 2000;(2):CD002006. Review. Update in: Cochrane Database Syst Rev 2004;(1):CD002006.

4 Johanson RB, Menon V. Vacuum extraction versus forceps for assisted vaginal delivery. Cochrane Database Syst Rev 1999;(2):CD000224. DOI:10.1002/14651858.CD000224.

5 Renfrew MJ, Hannah W, Albers L, Floyd E. Practices that minimize trauma to the genital tract in childbirth: a systematic review of the literature. Birth 1998;25:143-60.

6 Shipman MK, Boniface DR, Tefft ME, McCloghry F. Antenatal perineal massage and subsequent perineal outcomes: a randomized controlled trial. Br J Obstet Gynaecol subsequent perineal outcomes: a randomized controlled trial. Br J Obstet Gynaecol

7 McCandlish R, Bowler U, van Asten H. A randomised controlled trial of care of the perineum during second stage of normal labour. Br J Obstet Gynaecol 1998;105:1262 72.

8 Eason E, Labrecque M, Wells G, Feldman P. Preventing perineal trauma during childbirth: a systematic review. Obstet Gynecol 2000;182:76-80.

9 Pocock SJ. Clinical trials: a practical approach. Chichester: Wiley, 1983.

10 Melzack R. The short-form McGill pain questionnaire. Pain 1987;30:19-197.

11 Hodnett ED, Simmons-Tropea DA. The labour agentry scale: psychometric properties of an instrument measuring control during childbirth. Res Nurs Health 1987;10:301-10.

12 SikorskiJ, Wilson J, Clement S, Das S, Smeeton N. The antenatal care project: a randomised controlled trial comparing two schedules of antenatal visits. Final report. Department of Public Health Medicine, Division of Public Health Sciences, Guys and St Thomas's United Medical and Dental School, 1995.
13 Kumar RC, Robson KM, Smith AMR. Development of a self-administered questionnaire to measure maternal adjustment and maternal attitudes during pregnancy and after delivery.J Psychosom Res 1984;28:43-51.

14 Armitage P, Berry G, Matthews JNS. Statistical methods in medical research, 4th ed. Oxford: Blackwell Science, 2002.

15 Blankenbaker WL, DiFazio CA, Berry FA. Lidocaine and its metabolites in the newborn. Anesthesiology 1975;42:325-30.

16 Petrie RH, Paul WL, Miller FC. Placental transfer of lidocaine following paracervical block. Am J Obstet Gynecol 1974;120:791.

17 Philipson EH, Kuhnert BR, Syracuse CD. Maternal, fetal and neonatal lidocaine levels following local perineal infiltration. Am J Obstet Gynecol 1984;149:403-7.

18 Thomas J, Long G, Mather LE. Plasma lignocaine concentrations following topical Thomas J, Long G, Mather LE. Plasma lignocai
aerosol application. Br J Anaesthesia 1969;41:442.

19 Zandor G, Lindmark G, Nilsson BA. Pudendal block in normal vaginal delivery: clinical efficacy, lidocaine concentration in maternal and foetal blood, foetal and maternal acid-base values and influence on uterine activity. Acta Obstet Gynecol Scand (suppl) 1974;34:51-64.

20 Barker DP, Rutter N. Lignocaine ointment and local anaesthesia in preterm infants. Arch Dis Child 1995;72:F203-4.

21 Barrett DA, Rutter N. Percutaneous lignocaine absorption in newborn infants. Arch Dis Child 1994;71:F122-4.

22 Niven C, Gijsbers K. A study of labour pain using the McGill pain questionnaire. Soc Sci Med 1984;19:1347-51.

23 Waldenstrom U, Gottvall K. A randomised trial of birthing stool or conventional semirecumbent position for second stage labor. Birth 1991;18:5-10.

24 Stewart P, Spiby H. A randomized study of the sitting position for delivery using a newly designed obstetric chair. BrJ Obstet Gynaecol 1989;96:327-33.

(Accepted 27 April 2006)

doi 10.1136/bmj.38878.833241.7C

Department of Social Medicine, University of Bristol, Bristol BS8 2PR

Julia Sanders MRC HSR training fellow

Rona Campbell professor of health services research

Academic Unit of Primary Health Care, Department of Community Based

Medicine, University of Bristol

Tim J Peters professor of primary care health services research

Correspondence to:J Sanders, Midwifery Led Unit, University Hospital of Wales, Cardiff CF14 4XN julia.sanders@cardiffandvale.wales.nhs.uk 